\title{
Difference in the Gain in the Phototransduction Cascade Between Rods and Cones in Carp
}

\author{
(D) Naoto Kawakami ${ }^{1}$ and ${ }^{-S}$ Satoru Kawamura ${ }^{1,2}$ \\ ${ }^{1}$ Graduate School of Frontier Biosciences, and 2Department of Biological Sciences, Graduate School of Science, Osaka University, Yamada-oka 1-3, Suita, \\ Osaka 565-0871, Japan
}

In the vertebrate retina, there are two types of photoreceptors, rods and cones. Rods are highly light-sensitive and cones are less light-sensitive. One of the possible mechanisms accounting for the lower light-sensitivity in cones would be lower signal amplification, i.e., lower gain in the phototransduction cascade in cones. In this study, we compared the difference in the gain between rods and cones electrophysiologically in carp. The initial rising phases of the light responses were analyzed to determine an index of the gain, $G$, a parameter that can be used to compare the gain among cells of varying outer segment volumes. $G\left(\right.$ in $\left.\mathrm{fL} \cdot \mathrm{sec}^{-2}\right)$ was $91.2 \pm 14.8(n=5)$ in carp rods and $25.3 \pm 3.2(n=4)$ in carp red cones, so that the gain in carp red cones is $\sim 1 / 4$ of that in carp rods. $G$ was also determined in bullfrog rods and was $81.0 \pm 17.2(n=3)$ which was very similar to that in carp rods. The difference in the gain between rods and cones in carp determined in this study $(\sim 1 / 4$ in cones compared with rods) is consistent with that we recently determined biochemically ( $\sim 1 / 5$ in cones compared with rods). Together with the result obtained in bullfrog rods in this study and the results obtained by others, we concluded that the gain in the cascade is several-fold lower in cones than in rods in carp and probably in other animal species also.

\section{Introduction}

In the vertebrate retina, there are two types of photoreceptors, rods and cones. Rods are highly light-sensitive and mediate night vision, and cones are less light-sensitive and mediate daylight vision (Kawamura and Tachibanaki, 2008; Kefalov, 2012). Light responses in rods and cones are evoked through a well known phototransduction cascade consisting of visual pigment (R), transducin (Tr), cGMP phosphodiesterase (PDE), and cGMP-gated cation channel: $\mathrm{R}$ is activated $\left(\mathrm{R}^{\star}\right)$ by absorption of a photon, which leads to activation of $\operatorname{Tr}\left(\operatorname{Tr}^{*}\right)$ followed by activation of $\mathrm{PDE}$ $\left(\mathrm{PDE}^{\star}\right)$ to hydrolyze cGMP to result in the closure of the channel. Light-sensitivity of a rod or a cone is practically represented as the relation between response peaks and the intensities of stimulus light. A response peak is the point where the net decrease in the cGMP concentration is zero, which is attained by the balance between the hydrolysis of cGMP by $\mathrm{PDE}^{\star}$ and its synthesis by guanylate cyclase. In general, when the rate of hydrolysis of cGMP is lowered, light-sensitivity of a photoreceptor tends to be lowered. It is because lowered rate of cGMP hydrolysis is balanced easily with the cGMP synthesis to result in the reduction of the peak amplitude. Similarly, when the rate of synthesis of cGMP increases, light-sensitivity also tends to be lowered due to reduction of the peak amplitude.

\footnotetext{
Received Aug. 14, 2014; revised Sept. 9, 2014; accepted Sept. 21, 2014.

Author contributions: N.K. and S.K. designed research; N.K. and S.K. performed research; N.K. and S.K. analyzed data; S.K. wrote the paper.

This work was supported by Japan Society for the Promotion of Science Grants 20370060 and 23227002 to S.K. We thank Dr Shuji Tachibanaki for helpful comments.

The authors declare no competing financial interests.

Correspondence should be addressed to Satoru Kawamura, Graduate School of Frontier Biosciences, Osaka University, Yamada-oka 1-3, Suita, 0saka 565-0871, Japan. E-mail: kawamura@fbs.osaka-u.ac.jp.

DOI:10.1523/JNEUROSCI.3389-14.2014

Copyright $\odot 2014$ the authors $\quad 0270-6474 / 14 / 3414682-05 \$ 15.00 / 0$
}

It has been known that $>100$-fold signal amplification takes place in the phototransduction cascade in rods (Pugh and Lamb, 1993). The rate of rise of a response, which is a function of the rate of hydrolysis of cGMP, is dependent on this amplification in the cascade from $\mathrm{R}^{\star}$, via $\mathrm{Tr}^{\star}$, to $\mathrm{PDE}^{\star}$. One of the mechanisms of the lower light-sensitivity in cones, therefore, could be a lower gain of the amplification in the cascade in cones than in rods. We recently compared the rate of cGMP hydrolysis biochemically between carp rods and cones using their purified membrane preparations, and found that the gain in the cascade in cones is $\sim 1 / 5$ of that in rods (Tachibanaki et al., 2012; Koshitani et al., 2014). In the present study, to examine whether this biochemical conclusion is physiologically relevant or not, we compared the gain in the cascade between rods and cones electrophysiologically with use of intact rods and cones in carp, the same species used in our biochemical studies. Furthermore, to compare the gain in rods of different species, bullfrog rods were also examined.

To determine the gain electrophysiologically, we fitted the initial rise of a light response to a modified form of an equation introduced by Pugh and Lamb (1993). To monitor the changes in the cGMP concentration directly, light responses were recorded under whole-cell voltage-clamp conditions: the driving force of the current was maintained at a constant level and the effect of the membrane capacitance, which is much larger in cones, was eliminated.

\section{Materials and Methods}

Isolation of rods and cones. Carp (Cyprinus carpio, 15-20 cm in length; obtained from Matsuda Koi Farm, Niigata, Japan) and bullfrogs (Rana catesbeiana; supplied by Mr Ohuchi, Saitama, Japan) of either sex were dark-adapted at least for $3 \mathrm{~h}$. Their retinas were obtained after pithing the animal. Animal care was conducted according to the institutional guidelines (approvals, FBS-14-005 and -007). All of the cells were prepared in 
complete darkness with the aid of an infrared image converter (NVR 2015, NEC) under infrared illumination. Carp retinas were tore off with a pair of forceps in carp Ringer's solution $(119.9 \mathrm{~mm} \mathrm{NaCl}, 2.6 \mathrm{~mm} \mathrm{KCl}$, $0.5 \mathrm{~mm} \mathrm{CaCl}_{2}, 0.5 \mathrm{~mm} \mathrm{MgCl}_{2}, 0.5 \mathrm{~mm} \mathrm{MgSO}_{4}, 1 \mathrm{~mm} \mathrm{NaHCO}_{3}, 16 \mathrm{~mm}$ glucose, $0.5 \mathrm{~mm} \mathrm{NaH}_{2} \mathrm{PO}_{4}, 4 \mathrm{~mm}$ HEPES, pH 7.5). Large fragments of the retina were removed by filtration with a piece of a filter paper obtained from a usual surgical mask. The filtrate contained mechanically dissociated rods and cones as well as tiny fragments of the retina. As carp rods, we did not use dissociated rods because they deteriorated easily. Instead, the rods still attached to the retina were used: a few rods at the edge of a tiny fragment of the retina are accessible by an electrode, and they survive relatively long enough for the recording. As carp cones, we used mechanically dissociated cones consisting of the outer segment (OS) and the ellipsoid region. Dissociated bullfrog rods consisting of the OS and the ellipsoid region were obtained with a similar mechanical dissociation in frog Ringer's solution (115 mM NaCl, $3 \mathrm{~mm} \mathrm{KCl,} 2 \mathrm{mM} \mathrm{MgCl}_{2}, 2 \mathrm{~mm}$ $\mathrm{CaCl}_{2}, 10 \mathrm{~mm}$ glucose, $5 \mathrm{~mm}$ Tris, $\mathrm{pH}$ 7.5), and used for the recording.

Recordings of light responses. Cells were illuminated by a light flash (PZ42X, SUNPAK) to record their light responses. The half-duration of the flash was $0.7 \mathrm{~ms}$. Among four types of carp cones, we examined red-sensitive cones: the cones we used were large single cones and we confirmed that these cells show higher sensitivity to 600 than $500 \mathrm{~nm}$ light. Here, we call red-sensitive cones as "cones" for simplicity. Light intensity was attenuated with neutral density filters. All responses were recorded under whole-cell voltage-clamp conditions at $-30 \mathrm{mV}$ with a patch-clamp amplifier (EPC-7 Plus, HEKA). Signals were first low-pass filtered at $1 \mathrm{kHz}$. In most of the recordings of rod responses, signals were further low-pass filtered at $50 \mathrm{~Hz}$ and sampled at $100 \mathrm{~Hz}$. In one of the studies to determine the delay time of a rod response (see Fig. 3), signals were low-pass filtered and sampled both at $1 \mathrm{kHz}$. In the recordings of a cone response, signals low-pass filtered at $1 \mathrm{kHz}$ were sampled at $400 \mathrm{~Hz}$.

A whole-cell recording pipette was applied to the OS of a rod and to the ellipsoid region of a cone. The pipette solution contained $4 \mathrm{~mm}$ $\mathrm{NaCl}, 2.5 \mathrm{~mm} \mathrm{KCl}, 4.67 \mathrm{~mm} \mathrm{MgCl}_{2}, 111 \mathrm{~mm}$ potassium gluconate, 3 mM ATP, 3 mM GTP, 1 mM HEPES, pH 7.5. The pipette solution also contained $0.714 \mathrm{mM} \mathrm{CaCl}_{2}$ and $1 \mathrm{~mm}$ BAPTA to buffer the $\mathrm{Ca}^{2+}$ concentration at $500 \mathrm{~nm}$ (WEBMAXC EXTENDED; http://www. stanford.edu/ $\sim$ cpatton/webmaxc/webmaxcE.htm) which is close to the $\mathrm{Ca}^{2+}$ concentration in the dark in both rods and cones (Gray-Keller and Detwiler, 1994; Sampath et al., 1999). This $\mathrm{Ca}^{2+}$ buffer was used to inhibit the decrease in the cytoplasmic $\mathrm{Ca}^{2+}$ concentration $\left(\left[\mathrm{Ca}^{2+}\right]_{\mathrm{i}^{-}}\right.$ decrease) that takes place during a light response and facilitates the recovery of a light response. Carp or frog Ringer's solution was used as the bathing solution for the cells of carp or bullfrog, respectively.

Frequently, the whole-cell voltage-clamped cells deteriorated during recording and the response amplitude became smaller. For a reliable estimation of the gain, we gave just-saturating control light flashes periodically to record the maximum amplitude, and when necessary, the amplitude of a response recorded at intervening times was corrected by linear interpolation of the decrease of the maximum amplitude. Only in the case when the maximum amplitude changed minimally $(<30 \%)$, we used those responses for the analysis.

Estimation of the pigment bleach. We calibrated the intensity of light flash in the unit of fractional bleach as described previously (Takemoto et al., 2009). Visual pigments (rhodopsin in rods, and UV-/blue-/green-/ red-sensitive pigments in cones) were extracted with a detergent from purified carp rods and cones, or from purified bullfrog rods, and the light flash of known attenuation was given to bleach the extracted pigment(s) in a small test tube placed at the position of cells examined. The fraction of the bleach of each type of the pigment in a pigment solution was determined spectrophotometrically with partial bleaching. Based on this measurement, we estimated the fractional bleach of each type of the pigment in a solution at a given attenuation of the flash intensity. Visual pigment molecules in rods and cones absorb light polarized perpendicularly to the long axis of a rod or a cone, and the probability of absorption of a photon by a pigment in a rod or a cone is dependent on the angle between the direction of light propagation of a light flash and the long axis of a cell examined. We, therefore, calculated the fractional bleach of the pigment in a rod or a cone $(Y)$ with use of the fractional bleach in a solution as follows:

$$
Y=3 / 4 \cdot\left(1+\cos ^{2} \theta\right) \cdot X
$$

where $\theta$, known from a video image of a cell, is the angle between the direction of the propagation of light and the long axis of a rod or a cone, and $X$ is the fractional bleach calibrated in a pigment solution. Fractional bleach indicated in this study is that estimated with this equation.

Determination of the gain in the phototransduction cascade in rods and cones. Analysis of the rising phase of a light response in rods and cones was made by fitting the response time course to a theoretical expression of the closure of the cGMP-gated cation channel after a light flash (see Eq. 4). It is a modified form of the original equation introduced by Pugh and Lamb (1993):

$$
1-F(t)=1-\exp \left\{-0.5 \cdot \Phi \cdot A \cdot\left(t-t_{\mathrm{eff}}\right)^{2}\right\},
$$

where $F(t)$ is relative amplitude of a response; $\Phi$ is the number of pigment molecules bleached in a rod or a cone; $A\left(\right.$ in $\left.\mathrm{sec}^{-2}\right)$ is the amplification constant that reflects the amplification from $\mathrm{R}^{*}$ to cGMP hydrolysis; $t$ is the time after a light flash; $t_{\text {eff }}$ is the delay time of cGMP hydrolysis. To compare the gain among the cells of varying OS cytoplasmic volume $\left(V_{\text {cyto }}\right)$, not $A$ but the product, $V_{\text {cyto }} \cdot A$, should be compared (Pugh and Lamb, 1993). It is generally assumed that $V_{\text {cyto }}$ is approximately a half of the OS volume ( $V_{\text {os }}$ in fL in this study), and practically, $V_{\text {os }}$ can be used to compare the gain. However, it is not always possible to determine $V_{\text {os }}$ accurately. We circumvented this issue by using fractional bleach in a cell. In Equation 2, $\Phi$ is the number of pigment molecules bleached per cell, and it can be expressed as in Equation 3 with $V_{\text {os }}$, pigment concentration in a volume of $V_{\text {os }}$ ([pigment $]$ ), Avogadro's number $\left(N_{\mathrm{av}}\right)$ and fractional bleach $(Y)$ :

$$
\Phi=[\text { pigment }] \cdot V_{\mathrm{os}} \cdot N_{\mathrm{av}} \cdot Y .
$$

By introducing an index of the gain, $G$, Equation 2 is rewritten as follows:

$$
1-F(t)=1-\exp \left\{-0.5 \cdot[\text { pigment }] \cdot N_{\text {av }} \cdot Y \cdot G \cdot\left(t-t_{\text {eff }}\right)^{2}\right\},
$$

where $G=V_{\mathrm{os}} \cdot A$ (in $\left.\mathrm{fL} \cdot \mathrm{sec}^{-2}\right)$. The visual pigment concentration in $V_{\text {os }}$ ([pigment]) is known to be $3 \mathrm{~mm}$ generally (Hárosi, 1975), so that [pigment] $\cdot N_{\mathrm{av}}$ is a constant $\left(1.8 \times 10^{6}\right.$ molecules/fL $) . Y$ is known from Equation 1. With fitting the initial rising phase of a light response to Equation 4, we can determine $G$, and compare them in the phototransduction cascade directly among cells of varying $V_{\text {os }}$. The value of $t_{\text {eff }}$ was difficult to determine in responses of well below saturation, but the value was not so sensitive in the fitting of these small responses. We, therefore, used $t_{\text {eff }}$ determined in the response recorded at the highest intensity in a family of responses in Figures 1 and 2.

The time ranges used for the fitting were $20-300 \mathrm{~ms}$ in carp rods, $10-80 \mathrm{~ms}$ in carp cones and $20-600 \mathrm{~ms}$ in frog rods, although they were slightly varied in each of the fitting. With Equation 4, the fitting should be made in the time range where a response is not affected by the reactions contributing to the shut-off of the response (Pugh and Lamb, 1993). This condition is reasonably met in our study for two reasons. First, $\mathrm{R}^{\star}$, a molecule triggering the reactions to hydrolyze cGMP, is present during the time ranges used in both rods and cones: we previously estimated the lifetime of $\mathrm{R}^{*}$ in both carp rod and cone membranes in the presence of ATP by measuring the $\operatorname{Tr}^{\star}$ production time course, and they were $\sim 10 \mathrm{~s}$ in rod membranes and close to $125 \mathrm{~ms}$ in cone membranes (Tachibanaki et al., 2012). Second, the $\left[\mathrm{Ca}^{2+}\right]_{\mathrm{i}}$-decrease responsible for the acceleration of cGMP synthesis was inhibited in the present study with use of a $\mathrm{Ca}^{2+}$ buffer in the pipette solution. Although we cannot fully exclude the possibility of the contribution of the shut-off reactions in the time ranges used, their effects would be small.

\section{Results}

Difference in the gain between carp rods and cones

Figure 1 shows sample records of light responses obtained in a carp rod (Fig. 1B) and a carp cone (Fig. 1F). These responses were 
fitted to Equation 4 with known [pigment] $\cdot N_{\mathrm{av}} \cdot Y$ at each light intensity to obtain a unique value of the gain index, $G$, in a family of responses (global fitting; red dotted traces). We also obtained a flash intensity-response relation (Fig. 1C,G; obtained from Fig. 1B, $F$, respectively), and determined the flash intensity required for a half saturation of a light response $\left(I_{1 / 2}\right)$. Although it is not essential in this study (see Materials and Methods), we measured the outer segment volume $\left(V_{\text {os }}\right)$ from our video images and estimated the amplification constant $(A)$ in each cell. In the cells examined in Figure 1 , $G$ was $95.3 \mathrm{fL} \cdot \mathrm{sec}^{-2}$ in a rod and $29.9 \mathrm{fL} \cdot$ $\mathrm{sec}^{-2}$ in a cone, and $G$ in this cone was $1 / 3.2(29.9 / 95.3)$ of that in the rod examined in Figure 1. In Table 1, the parameters determined from five carp rods and four cones are summarized. $G$ in cones was $\sim 1 / 4(25.3 / 91.2)$ of that in carp rods in these groups of cells.

Estimation of the gain in bullfrog rods Figure $2 B$ shows sample records of a family of light responses obtained in a bullfrog rod. The responses were fitted to Equation 4 similarly as in Figure 1. The parameters determined are summarized in Figure 2D. G obtained from the cell shown was $86.4 \mathrm{fL} \cdot \mathrm{sec}^{-2}$, and the average in 3 bullfrog rods was $81.0 \pm 17.2 \mathrm{fL}$ - $\sec ^{-2}$ (Table 1). It should be mentioned that although the average $V_{\text {os }}$ was $\sim 20$-fold (1890 fL/96.2 fL) larger in bullfrog rods than in carp rods, the values of $G$ in these rods were very similar $(81.0 \pm 17.2$ in bullfrog rods and $91.2 \pm$ 14.8 in carp rods; Table 1 ).

\section{Difference in the delay time between carp rods and cones}

As summarized in Table 1, the delay time ( $\left.t_{\text {eff }}\right)$ determined under the conditions used in Figure 1 was shorter in cones than in rods in carp. However, the highest light intensity used in these recordings was $\sim 8 \times 10^{-6}$ fractional bleach in rods and was $\sim 10$ times lower than that used in cones $\left(\sim 8 \times 10^{-5}\right.$ fractional bleach). The delay time is shortened with increase in the flash intensity in both rods and cones (Hestrin and Korenbrot, 1990), and for this reason, the delay time should be compared under the condition that the hydrolytic rate of cGMP is similar in rods and cones. Because the gain is $\sim 1 / 4$ in cones compared with rods (this study), the light intensity lowered by four times from that used for the stimulation of cones should be used in rods to compare the delay time between rods and cones. As shown in Figure 3, even under this condition, the delay time was shorter in cones $(8.0 \mathrm{~ms}$ at $0.9-$ $1.1 \times 10^{-4}$ fractional bleach; red traces) than in rods $(10.3 \mathrm{~ms}$ at $2.6 \times 10^{-5}$ fractional bleach; black traces). One noticeable point is that the rates of rise of responses are similar in rods and cones in these records. This similarity is another line of evidence that the gain of the phototransduction is several-fold lower in cones than in rods. At a lower light intensity of $8.3 \times 10^{-6}$ fractional bleach

B
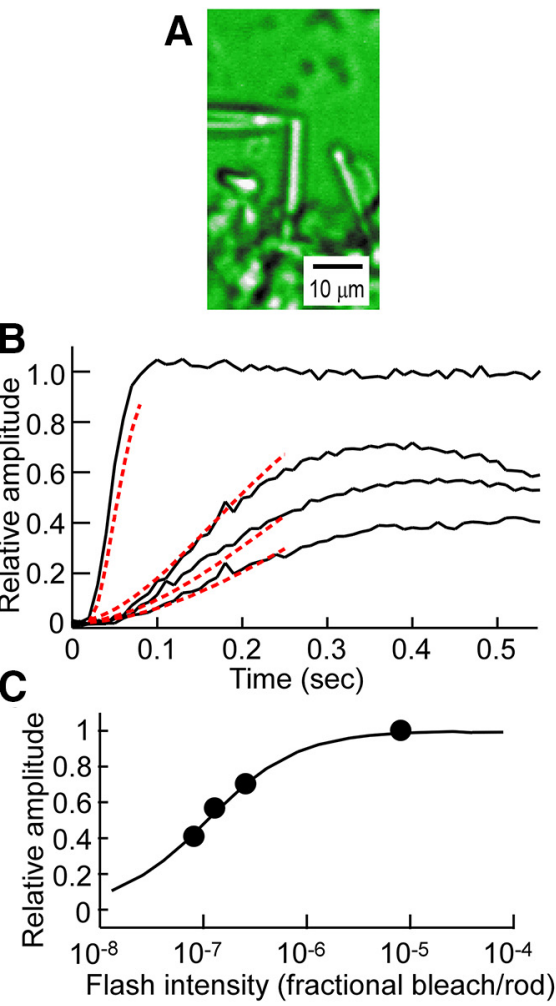

Figure 1. Comparison of $G$ between a rod and a cone in carp. $A, A$ carp rod was whole-cell voltage-clamped. $B$, A series of light flashes of varying intensities was given to obtain a family of light responses. The initial rising phases were fitted globally to Equation 4 using a unique value of $G$ (red dotted traces). The flash intensities used were (from the dimmest): $8.2 \times 10^{-8}, 1.3 \times$ $10^{-7}, 2.6 \times 10^{-7}$, and $8.2 \times 10^{-6}$ fractional bleach. $C$, The flash intensity-response amplitude relation is plotted. Filled circles fitting and measured $\boldsymbol{V}_{0 \mathbf{s}} \boldsymbol{E} \boldsymbol{E} \boldsymbol{H}$, Similar recordings were made in a carp cone, and the results are shown as in $\boldsymbol{A}-\boldsymbol{D}$. The flash intensities used in $\boldsymbol{F}$ were (from the dimmest): $1.3 \times 10^{-6}, 2.6 \times 10^{-6}, 8.1 \times 10^{-6}$, and $8.1 \times 10^{-5}$ fractional bleach. Each response shown in $\boldsymbol{B}$ and $\boldsymbol{F}$ is an average of at least two records.

in a rod, the rate of rise, and therefore the rate of cGMP hydrolysis, was lower, and the delay time was longer (Fig. 3, gray trace).

\section{Discussion}

In the present study, we found electrophysiologically that the gain in the phototransduction cascade in cones is $\sim 1 / 4$ of that in rods in carp. We further found that the gain is very similar in carp rods and bullfrog rods.

Gain and light-sensitivity differences between rods and cones In our recent biochemical studies, we compared the efficiencies of the activation of $\operatorname{Tr}$ by $R^{\star}$ and the activation of PDE by $\operatorname{Tr}^{\star}$. Our findings were that the efficiency of $\mathrm{Tr}$ activation by $\mathrm{R}^{*}$ in carp cones is $\sim 1 / 5$ of that in carp rods (Tachibanaki et al., 2012) and that the efficiency of PDE activation by $\mathrm{T}^{\star}$ is similar in carp rods and cones (Koshitani et al., 2014). It has been shown that the quantum yield of a visual pigment is similar in rods and cones (Okano et al., 1992), and the specific activities of $\mathrm{PDE}^{\star}$ in rods and cones are very similar (Gillespie and Beavo, 1988). Furthermore, expression levels of R (Hárosi, 1975), $\operatorname{Tr}$ (Koshitani et al., 
A

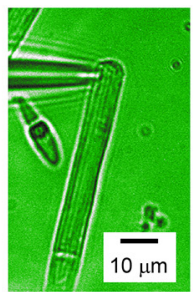

C

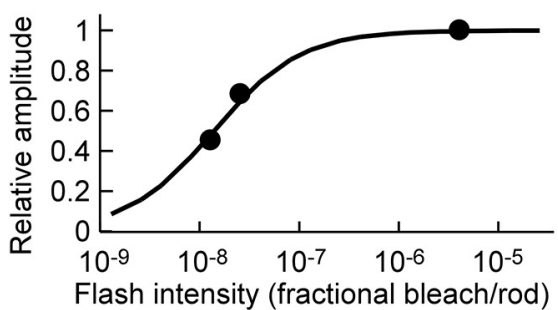

B

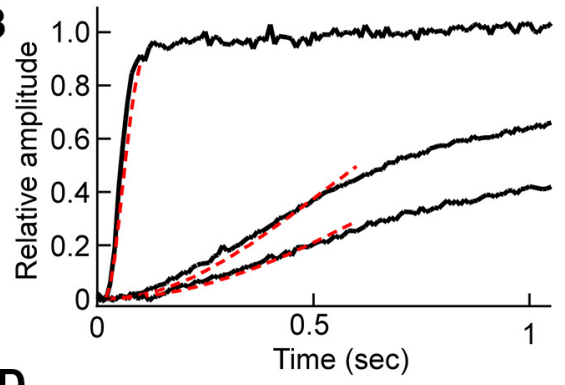

Figure 2. Estimation of $G$ in a bullfrog rod. $A, A$ bullfrog rod was whole-cell voltage-clamped. $B$, A series of light flash of varying intensities was given to obtain a family of light responses. The initial rising phases were fitted globally to Equation 4 using a unique value of $G$ (red dotted traces). The flash intensities were (from the dimmest): $1.3 \times 10^{-8}, 2.6 \times 10^{-8}$, and $4.1 \times 10^{-6}$ fractional bleach. Each response shown in $B$ is an average of at least two records. $C$, The flash intensity-response amplitude relation. Filled circles are the data points obtained in $\boldsymbol{B}$ and the solid curve indicates a Michaelis-Menten relation. $\boldsymbol{D}$, Parameters determined by the fitting and measured $V_{\text {os }}$.

Table 1. Summary of the parameters determined

\begin{tabular}{lccc}
\hline & \multicolumn{1}{l}{ Carp } & \multicolumn{2}{l}{ Bullfrog } \\
\cline { 2 - 3 } & $\operatorname{Rod}(n=5)$ & $\operatorname{Cone}(n=4)$ & $\operatorname{Rod}(n=3)$ \\
\hline$G\left(\mathrm{fL} \cdot \mathrm{sec}^{-2}\right)$ & $91.2 \pm 14.8$ & $25.3 \pm 3.2$ & $81.0 \pm 17.2$ \\
$t_{\text {eff }}(\mathrm{msec})$ & $16.2 \pm 1.9$ & $6.2 \pm 0.7$ & $17.7 \pm 4.0$ \\
$V_{\text {os }}(\mathrm{fL})$ & $96.2 \pm 20.1$ & $100.8 \pm 37.4$ & $1890 \pm 250$ \\
$A\left(\mathrm{sec}^{-2}\right)$ & $0.988 \pm 0.283$ & $0.283 \pm 0.123$ & $0.0431 \pm 0.0101$ \\
$I_{1 / 2}($ fractional & $9.5 \pm 3.5 \times 10^{-8}$ & $4.5 \pm 0.9 \times 10^{-6}$ & $1.4 \pm 0.4 \times 10^{-8}$ \\
$\quad$ bleached/cell) & & & \\
\hline
\end{tabular}

Values are shown as mean $\pm S D$. The number of the cells used is shown in parentheses.

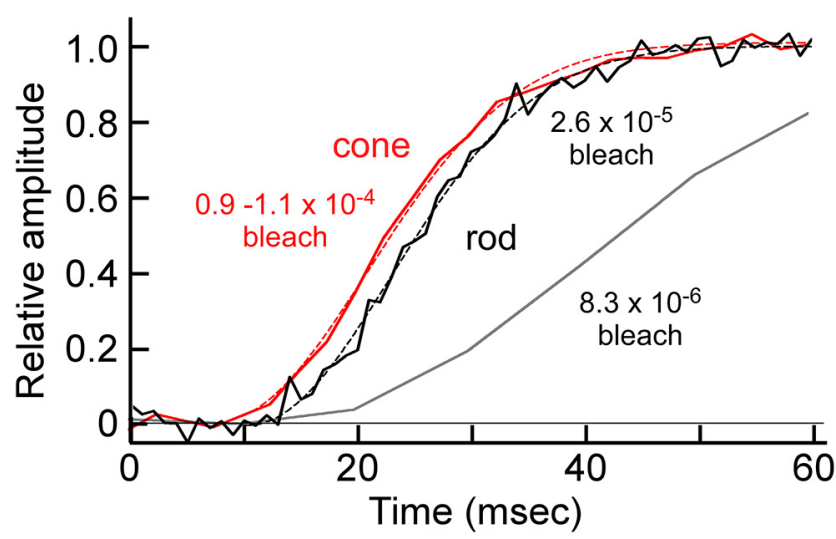

Figure 3. Difference in the delay time between rods and cones in carp. Light responses were recorded by giving a light flash of $2.6 \times 10^{-5}$ fractional bleach to a rod (black solid trace, an average of 21 records from 3 rods) or giving a light flash of $0.9-1.1 \times 10^{-4}$ fractional bleach to a cone (red solid trace, an average of 5 records from 5 cones). Each of the records was fitted to Equation 4 (black and red dotted traces). The determined parameters in rods were $G=132 \mathrm{fL} \cdot$ $\mathrm{sec}^{-2}$ and $t_{\text {eff }}=10.3 \mathrm{~ms}$, and those in cones were $G=36.3 \mathrm{fL} \cdot \mathrm{sec}^{-2}$ and $t_{\text {eff }}=8.0 \mathrm{~ms}$. The response evoked by a light flash of lower intensity $\left(8.3 \times 10^{-6}\right.$ fractional bleach) in rods is also shown (gray trace, an average of 10 records from 4 rods), and the determined parameters were $G=104 \mathrm{fl} \cdot \mathrm{sec}^{-2}$ and $t_{\text {eff }}=13.5 \mathrm{~ms}$.
2014), and PDE (Gillespie and Beavo, 1988) are all similar in rods and cones. From these results, we biochemically concluded that the gain of the amplification in the cascade in cones is $\sim 1 / 5$ of that in rods (Koshitani et al., 2014). As shown in the present electrophysiological study, the gain in the phototransduction cascade in cones is $\sim 1 / 4$ of that in rods in carp. Because two different experimental approaches gave a very similar value as the difference in the gain between rods and cones, we concluded that the gain is several-fold lower in cones than in rods in carp.

Lower gain in carp cones would be one of the reasons for the lower lightsensitivity in cones than in rods. However, we previously observed that the lightsensitivity of a carp cone is $\sim 400$-fold lower than that of a carp rod based on the difference in $I_{1 / 2}$ determined with the suction electrode method (Kawamura and Tachibanaki, 2008). Therefore, the several-fold lower gain in cones only partly explains the lower light-sensitivity in cones than in rods. There are potentially two additional mechanisms that account for the lower light-sensitivity in cones. First, facilitation of cGMP synthesis due to the $\left[\mathrm{Ca}^{2+}\right]_{\mathrm{i}}$-decrease is known to greatly reduce the light-sensitivity (Mendez et al., 2001), and this effect could be larger in cones (see below). Second, lifetimes of $\mathrm{R}^{*}$ and $\mathrm{Tr}^{*}$ are shorter in cones than in rods, and due to these shorter lifetimes of activated species, total number of $\mathrm{PDE}^{\star}$ molecules produced by light flashes of the same intensity is lower in cones than in rods (Koshitani et al., 2014), which also contributes to lower the light-sensitivity in cones.

In the presence of $\mathrm{Ca}^{2+}$ buffers, i.e., when the $\left[\mathrm{Ca}^{2+}\right]_{i}$ decrease is inhibited, light-sensitivity in both rods and cones increases (Fain et al., 1989; Matthews et al., 1990). The effect is larger in cones $(\sim 10$-fold; Matthews et al., 1990$)$ than rods ( $\sim 4.3$-fold; Fain et al., 1989) in salamander. The larger effect of the inhibition of the $\left[\mathrm{Ca}^{2+}\right]_{\mathrm{i}}$-decrease in cones was also observed in carp. The $I_{1 / 2}$ values previously observed with suction electrode recordings in the absence of a $\mathrm{Ca}^{2+}$ buffer were $1.7 \times 10^{-7}$ fractional bleach in rods and $6.6 \times 10^{-5}$ fractional bleach in cones in carp (Kawamura and Tachibanaki, 2008). In the presence of the $\mathrm{Ca}^{2+}$ buffer in the present study, $I_{1 / 2}$ decreased by 1.8 -fold $\left(1.7 \times 10^{-7}\right.$ to $9.5 \times 10^{-8}$ fractional bleach $)$ in rods and by 15 -fold $\left(6.6 \times 10^{-5}\right.$ to $4.5 \times 10^{-6}$ fractional bleach) in cones in carp (Table 1). This higher effect of a $\mathrm{Ca}^{2+}$ buffer in cones suggests higher effect of the $\left[\mathrm{Ca}^{2+}\right]_{\mathrm{i}}$-decrease in cones than in rods under in vivo conditions. This effect of a $\mathrm{Ca}^{2+}$ buffer explains a smaller difference in $I_{1 / 2}$ between rods and cones in this study ( $\sim 50$-fold: $9.5 \times 10^{-8}$ fractional bleach in rods and $4.5 \times$ $10^{-6}$ fractional bleach in cones; Table 1) than in our previous suction electrode recordings ( $\sim 400$-fold). We assume that this higher effect of the $\left[\mathrm{Ca}^{2+}\right]_{i}$-decrease could be due to higher expression levels of visinin, a cone homolog of S-modulin/recoverin (Arinobu et al., 2010), and guanylate cyclase and GCAP (Takemoto et al., 2009) in cones than in rods.

In Figure 3, at the light-intensity inducing $10^{-5}-10^{-4}$ fractional bleach, the delay time $\left(t_{\text {eff }}\right)$ was shorter in cones $(8.0 \mathrm{~ms})$ than in rods (10.3 ms) in carp at a similar cGMP hydrolytic rate. This result suggests that cGMP hydrolysis requires more time in 
rods than in cones possibly because of the presence of higher amplification, and/or that the structure of the OS in cones is effective in shortening the delay time at just a saturating intensity of light. Hestrin and Korenbrot (1990) reported that the delay time is similar in salamander rods and cones. However, their study was made by giving highly saturating intensity of light. Because the delay time is shortened with increasing the light intensity (our Fig. 3; Hestrin and Korenbrot, 1990), the apparent inconsistency between our and their findings would be simply because the flash intensities they used were much higher than ours $\left(\sim 10^{-2}\right.$ vs $10^{-5}-10^{-4}$ fractional bleach $)$. It is possible that the delay times they observed are the shortest limit in both rods and cones.

\section{Comparison of the gain among rods and cones in different animal species}

As shown in this study, the gain in bullfrog rods was very similar to that in carp rods, and their $G$ values were $80-90 \mathrm{fL} \cdot \mathrm{sec}^{-2}$. Although there might be difficulties in the estimation of $A$ and $V_{\text {os }}$ in mice, Nikonov et al. (2006) estimated $A$ from responses obtained with the suction electrode method and also $V_{\text {os }}$ in mouse rods and cones. $A$ and $V_{\text {os }}$ in rods were $\sim 8 \mathrm{~s}^{-2}$ and $37 \mathrm{fL}$, respectively, so that $G\left(=V_{\mathrm{os}} \cdot A\right)$ in mouse rods is $\sim 300 \mathrm{fL} \cdot \mathrm{sec}^{-2}$. In mouse cones, $A$ values were estimated as $3.2 \mathrm{~s}^{-2}$ in M-cones and $4.5 \mathrm{~s}^{-2}$ in $\mathrm{S}$-cones, and the values of $V_{\text {os }}$ were $14 \mathrm{fL}$ for both cones, so that $G$ values are $45 \mathrm{fL} \cdot \mathrm{sec}^{-2}$ in $\mathrm{M}$-cones and $63 \mathrm{fL} \cdot$ $\mathrm{sec}^{-2}$ in S-cones. $G$ values in cones are, therefore, $\sim 1 / 7-1 / 5$ of that in a rod in mice. This difference in $G$ between mouse rods and cones is very similar to that in carp $(\sim 1 / 4)$.

$G$ in mouse rods $\left(\sim 300 \mathrm{fL} \cdot \mathrm{sec}^{-2}\right)$ is $3-4$ times larger than those of carp $\left(\sim 90 \mathrm{fL} \cdot \mathrm{sec}^{-2}\right)$ and bullfrog $\left(\sim 80 \mathrm{fL} \cdot \mathrm{sec}^{-2}\right)$, and those of mouse cones $\left(45 \mathrm{fL} \cdot \mathrm{sec}^{-2}\right.$ in $\mathrm{M}$-cones and $63 \mathrm{fL} \cdot \mathrm{sec}^{-2}$ in S-cones) are similarly two to three times larger than that in carp cones $\left(\sim 25 \mathrm{fL} \cdot \mathrm{sec}^{-2}\right)$. It is known that the temperaturedependency of $A$, and therefore that of $G$, is $\sim 3.5$ in toad rods (Pugh and Lamb, 1993), so that this two to four times difference in $G$ observed in both rods and cones between carp and mouse can be explained by the difference in the temperature at which the light responses were recorded: $37^{\circ} \mathrm{C}$ in mice and $\sim 25^{\circ} \mathrm{C}$ in carp. This consideration together with the finding that $G$ is similar in rods having different $V_{\text {os }}$ (carp and bullfrogs) implies that the gain in rods (and also in cones) is very similar among species when the temperature is the same, and that the gain in the phototransduction cascade is several-fold lower in cones than in rods regardless of animal species, as suggested by Pugh and Lamb (1993).

\section{References}

Arinobu D, Tachibanaki S, Kawamura S (2010) Larger inhibition of visual pigment kinase in cones than in rods. J Neurochem 115:259-268. CrossRef Medline

Fain GL, Lamb TD, Matthews HR, Murphy RL (1989) Cytoplasmic calcium as the messenger for light adaptation in salamander rods. J Physiol 416: 215-243. Medline

Gillespie PG, Beavo JA (1988) Characterization of a bovine cone photoreceptor phosphodiesterase purified by cyclic GMP-sepharose chromatography. J Biol Chem 263:8133-8141. Medline

Gray-Keller MP, Detwiler PB (1994) The calcium feedback signal in the phototransduction cascade of vertebrate rods. Neuron 13:849-861. CrossRef Medline

Hárosi FI (1975) Absorption spectra and linear dichroism of some amphibian photoreceptors. J Gen Physiol 66:357-382. CrossRef Medline

Hestrin S, Korenbrot JI (1990) Activation kinetics of retinal cones and rods: response to intense flashes of light. J Neurosci 10:1967-1973. Medline

Kawamura S, Tachibanaki S (2008) Rod and cone photoreceptors: molecular basis of the difference in their physiology. Comp Biochem Physiol A Mol Integr Physiol 150:369-377. CrossRef Medline

Kefalov VJ (2012) Rod and cone visual pigments and phototransduction through pharmacological, genetic, and physiological approaches. J Biol Chem 287:1635-1641. CrossRef Medline

Koshitani Y, Tachibanaki S, Kawamura S (2014) Quantitative aspects of cGMP phosphodiesterase activation in carp rods and cones. J Biol Chem 289:2651-2657. CrossRef Medline

Matthews HR, Fain GL, Murphy RL, Lamb TD (1990) Light adaptation in cone photoreceptors of the salamander: a role for cytoplasmic calcium. J Physiol 420:447-469. Medline

Mendez A, Burns ME, Sokal I, Dizhoor AM, Baehr W, Palczewski K, Baylor DA, Chen J (2001) Role of guanylate cyclase-activating proteins (GCAPs) in setting the flash sensitivity of rod photoreceptors. Proc Natl Acad Sci U S A 98:9948-9953. CrossRef Medline

Nikonov SS, Kholodenko R, Lem J, Pugh EN Jr (2006) Physiological features of the $\mathrm{S}$ - and $\mathrm{M}$-cone photoreceptors of wild-type mice from singlecell recordings. J Gen Physiol 127:359-374. CrossRef Medline

Okano T, Fukada Y, Shichida Y, Yoshizawa T (1992) Photosensitivities of iodopsin and rhodopsins. Photochem Photobiol 56:995-1001. CrossRef Medline

Pugh EN Jr, Lamb TD (1993) Amplification and kinetics of the activation steps in phototransduction. Biochim Biophys Acta 1141:111-149. CrossRef Medline

Sampath AP, Matthews HR, Cornwall MC, Bandarchi J, Fain GL (1999) Light-dependent changes in outer segment ad libitum- $\mathrm{Ca}^{2+}$ concentration in salamander cone photoreceptors. J Gen Physiol 113:267-277. CrossRef Medline

Tachibanaki S, Yonetsu S, Fukaya S, Koshitani Y, Kawamura S (2012) Low activation and fast inactivation of transducin in carp cones. J Biol Chem 287:41186-41194. CrossRef Medline

Takemoto N, Tachibanaki S, Kawamura S (2009) High cGMP synthetic activity in carp cones. Proc Natl Acad Sci U S A 106:11788-11793. CrossRef Medline 